\title{
Bundestagswahl 2009: Reichhaltige Informationen, originell interpretiert
}

\author{
Machnig, Matthias und Joachim Raschke (Hrsg.): Wohin steuert Deutschland? Bundestagswahl \\ 2009. Ein Blick hinter die Kulissen, Hoffmann und Campe Verlag, Hamburg 2009, 352 Sei- \\ ten, $€ 19,95$.
}

Der vor der Bundestagswahl 2009 erschienene Sammelband von Matthias Machnig und Joachim Raschke bringt viele Ursachen für das zu erwartende Ergebnis zur Sprache und leuchtet zentrale Problemfelder der Politik aus. Mehr als 30 renommierte Autoren - Politiker, Publizisten, (Politik-)Wissenschaftler - kommen zu den Themen „Führung“, „Strategie“, „Reform“, „Programm“, „Parteien“, „Bündnisfragen“ und „Kommunikation“ zu Wort. Zwei Beiträge der Herausgeber rahmen das Werk ein. Der eine zielt auf die strategischen Ausgangsbedingungen der Parteien. Lagerpolitik werde die Gewichte zu den „Rändern“"verschieben - „zu den Flügelparteien FDP und Linke“ (S. 25). Die Termini „Ränder“ und „Flügelparteien“ für diese beiden Kräfte mögen formal richtig sein, inhaltlich sind sie es nicht. Der andere Beitrag ist skeptisch gestimmt. Das Ergebnis der Wahl sei eine bloße Momentaufnahme. Und: „Ohne klare Alternativen in der Wahl weiß man hinterher nicht, was die Wähler mit ihrem Votum gemeint haben“ (S. 343).

$\mathrm{Zu}$ Recht ist wenig vom Rechtsextremismus die Rede, da dieser aufgrund seiner Schwäche - das Aufgehen der „Phantompartei“ DVU in der NPD ändert daran nichts - die Grundlagen des demokratischen Verfassungsstaates nicht zu gefährden vermag, hingegen viel - ebenso zu Recht - von der Partei „Die Linke“ (ein strategisch geschickt gewählter Name). Die Journalistin Brigitte Fehrle sagte der Partei große Erfolge im "Superwahljahr“ 2009 voraus. So traf es in der Tat zu. Allerdings erwähnt sie auch, dass sich die Stimmengewinne nicht auf Regierungsebene niederschlagen würden, denn die SPD hatte vorher klar eine Koalition mit der Partei auf Bundesebene abgelehnt (und sich nach der Bundestagswahl 2005 an ihr Versprechen gehalten). Gregor Gysi, der populärste Politiker der Linken, meint, zum ersten Mal seit 1949 existiere eine gesellschaftlich anerkannte linke Partei jenseits der SPD. Das stimmt. Er behauptet jedoch, die SPD sei für die Linke wegen ihrer Agenda 2010 und wegen der "völkerrechtswidrigen Kriege“ (S. 206) nicht koalitionsfähig. Tatsächlich jedoch will Gysi nicht zugeben, dass die SPD sich - bisher - weigert, auf Bundesebene eine Koalition mit der Linken einzugehen. Der Berliner Politikwissenschaftler Gero Neugebauer stellt die unterschiedlichen Spektren der in sich nicht einigen Partei detailliert vor. Dabei wird die starke Rolle Oskar Lafontaines betont. Die Handlungsfähigkeit der Partei gerate dann in Gefahr, ,wenn sich die Beziehungen zwischen Lafontaine und der Linken lockerten oder wenn sich die SPD zu einem Bündnis mit der Linken auf Bundesebene bereitfände" (S. 249). Nirgendwo ist von den extremistischen Zügen der Linken die Rede. Sie gilt zuweilen als politikunfähig, aber nicht als demokratieunfähig.

Der Publizist Gabor Steingart - ein bekennender Nichtwähler ${ }^{1}$ - stellt die „Selbsterneuerung der Demokratie“ in den USA unter Barack Obama vor: unter anderem „Politik mit Volk“, „Persönlichkeit vor Parteilichkeit“, „Kommunikation statt Agitation“, „Sachlichkeit vor Parteilichkeit“. Aus den USA lasse sich die Erneuerung der Demokratie lernen. Vielleicht idealisiert der Autor die dortigen Verhältnisse etwas und perhorresziert die hiesigen. Gleichwohl: Die Zahl der Stammwähler schrumpft, die der Nicht- und Wechselwähler 
steigt - auf Kosten der großen Kräfte, die unterschiedliche Interessen bündeln (müssen) und „Wohlfühlwahlkämpfe“ betreiben, um niemanden vor den Kopf zu stoßen. Der scharfe Parteienkritiker Hans Herbert von Arnim hat für den Stimmenrückgang der großen Parteien pointiert die griffige Formel von den „Volksparteien ohne Volk“ geprägt. ${ }^{2}$ Mehrere Autoren, so Warnfried Dettling und Manfred Bissinger, analysieren die Schwächen der Volksparteien. Dettling rät der CDU, die Grünen in ein Regierungsbündnis einzubeziehen, Bissinger der SPD, gleiches mit der Linken zu tun.

Die Tatsache, dass der Stimmenanteil der großen Parteien sich künftig vielleicht bei 30 Prozent einpendeln könnte, muss Konsequenzen für die Strategien haben. Herkömmliche Zweierbündnisse dürften weniger vorkommen, da Große Koalitionen nicht dem Musterfall einer parlamentarischen Demokratie entsprechen und Minderheitsregierungen in Deutschland, im Gegensatz zu Skandinavien, keineswegs akzeptiert sind. Bei Dreierbündnissen bieten sich drei Varianten an: eine „schwarze“ Ampel-Koalition (CDU/CSU, FDP und Grüne), eine „normale“ Ampel-Koalition (SPD, FDP und Grüne) oder ein „Linksbündnis“ (SPD, Grüne und Linke). Unter dem Stichwort „Bündnisfragen“ stellen Autoren Überlegungen (zu Strategien und Prognosen) an, etwa der Berliner Parteienforscher Oskar Niedermayer, der wahrscheinliche und unwahrscheinliche Koalitionen erörtert. Die Grünen, ohne die keine der drei „Dreierkoalitionen“ auskommt, seien in einer „koalitionsstrategischen Schlüsselposition“ (S. 276). Wenn die Bürger vor der Wahl wissen, dass SPD, Grüne und Linke ein Bündnis anstreben, jedenfalls nicht ausschließen, dürfte ein Teil traditioneller Sozialdemokraten diesen Weg, den sie als irrig ansehen, ebenso ablehnen wie ein Teil der Wähler der Grünen. Der Wahlforscher Matthias Jung weist entschieden auf diesen Sachverhalt hin. „Nicht nur, dass gut zwei Drittel der Gesamtheit dieses Koalitionsmodell schlecht finden, auch die Anhänger der für eine solche Koalition notwendigen weiteren Parteien sprechen sich mehrheitlich dagegen aus“ (S. 286). In einer „beschleunigten Stimmungsdemokratie“ (Jörg Schönenborn, S. 308) ist allerdings ein schneller Wandel der Partei- und Koalitionspräferenzen möglich.

In einigen Bereichen hat die deutsche Einheit zu fundamentalen Veränderungen auch im Westen des Landes geführt, in anderen eher ein hohes Maß an Kontinuität gezeigt. Wer die Frage untersucht, ob das vereinigte Deutschland - gut 20 Jahre nach dem Fall der Mauer - eher eine neue oder eine erweiterte Bundesrepublik darstellt, kommt nicht umhin, eine Vielzahl an Bereichen zu berücksichtigen: die institutionelle Ordnung, das wirtschafts- und sozialpolitische System, die Politische Kultur, den politischen Extremismus, die streitbare Demokratie, die außenpolitische Orientierung und andere. Anders als der Obertitel andeutet, fehlen solche Analysen in diesem Band. ${ }^{3}$

Am schwächsten fällt das Kapitel „Programme“ aus. Jürgen Rüttgers, Andrea Nahles, Wolfgang Gerhardt, Gregor Gysi und Reinhard Bütikofer schreiben das, was von ihnen zu erwarten war. Kantige Positionen finden sich nicht, Leerformeln schon. Ungeachtet dessen: Dieses Buch ist aufgrund seines Informationsreichtums, der originellen Interpretationen und seiner analytischen Kraft nicht überholt.

Eckhard Jesse

2 Vgl. Hans Herbert von Arnim, Volksparteien ohne Volk. Das Versagen der Politik, München 2009.

3 Vgl. Heike Tuchscheerer, 20 Jahre vereinigtes Deutschland: Eine „neue“ oder „erweiterte Bundesrepublik“?, Baden-Baden 2010. 